Structural Eng. / Earthquake Eng. Vol.5. No.1, 51s-60s. April 1988

Japan Society of Civil Engineers (Proc. of JSCE No.392/I-9)

\title{
A STATISTICAL STUDY ON LIFE TIME OF BRIDGES
}

\author{
By Hiroshi IIZUKA*
}

\begin{abstract}
This study is to estimate statistically the life time of bridges and to analyse the reason of demolish and renewal. Data sources are the ledgers of bridge in Niigata prefecture, from which the numbers of remaining bridges and demolished ones were took out in order of newly built year. Total of remaining bridges are 4333 and demolished ones are 44 at 1986.

Using terms of reliability theory, the "probability density function of failure" is supposed to follow a weibull distribution from graphic analysis, and by the presumed reliability function, the life expectancy of steel bridge are estimated at some 35 years and of reinforced concrete bridge are at some 54 years. Concerning reason of demolish, using information theory, the contributed ratio of information are calculated. Political or functional reason are superior to physical reason.

Keywords: bridge, maintenance, life time
\end{abstract}

\section{INTRODUCTION}

In order to maintain structures such as bridges effectively, we should know how long we will use and imagine its life cycle during which it is repeatly repaired and demolished.

Concerning life time of bridges, there are already many studies ${ }^{1)}$ done from several viewpoints, but there are few which were done by statistical analysis.

For example, by assessment of bearing force ${ }^{2)}$, the comprehensive study of life time ${ }^{3)}$, the study on transitional change of law and specification, the accumulation of references and experimences ${ }^{4)}$, and etc. They are very complex and include many factors. They are devided generally into two types, one is a general survey and the other is particular one. The former is on a large scale and the latter is more precise but can be insufficient in its sample. Both method will compensated each other since the data and value of life time will converged. This study is done between both point of views and the data is limitted into particular region and age, but by using actual data and by analyzing statistically, it will contribute to the consideration of life time.

This paper presents an actual situation of the remaining and demolished bridges in Niigata prefecture by using a new method from the field of architecture ${ }^{5)}$. From the ledgers, by using population statistics and by applying reliability theory, the average remaining durable years are estimated.

Moreover, as durable years are influenced by other aspects such as physical, social and functional aspects, the reason of demolish are analysed using information theory $y^{(i)}$.

\section{METHOD OF SURVEY}

\section{(1) Bridges being investigated}

\footnotetext{
* Member of JSCE, D. Eng. . Professor, Univ. of Niigata
} 
a) Data utilization and the compilation method

This study use the data from Bridge Status and Explanation in 1976 of Niigata prefecture. The age of the one which were built in 1976 is 0 and so on. In using the age of demolished one we take the established age from the demolished age.

b) Remaining and demolished bridge

They are devided into two groups, steel and concrete, which then are sorted by its age and are shown as Fig. 1 and Fig. 2.

$\begin{array}{llr}\text { Remaining bridge } & \text { steel } & 763 \\ & \text { concrete } & 3570 \\ \text { Demolished bridge } & \text { steel } & 20 \\ & \text { concrete } & 24\end{array}$

\section{(2) The method of analysis}

a) Life time

From dictionary, "Life time is the age of a durable property which were decided by structural, physical and social factor. In other case it is actual and theoretical mean, and it can be seen in a fitted property tax ..."

In ordinance issued by the Finance Ministry, Life time of building or structure which are used for calculating the fixed property tax are decided by structural types and its utilities. For example, reinforced bridge is 50 years and steel bridge is 40 years. But this consideration is due to tax and not the real age. Actually it must include social, administrative, functional, fashional, or natural factor, thus can have many different types of ages.

In this paper, from statistical data, the sum of average life time is presumed by Cumulative Hazard Method and the life expectancy is calculated by population statistics.

Moreover, average life time is estimated due to its demolishing reason and the contributed ratio of its factor which were derived from information theory.

b) The estimation of life time by Cumulative Hazard Method

1) Demolish ratio, remaining ratio and average life time

The purpose here is to dictate phenomenon of age reduction which are modeled by using data and to estimate its life time. To analyse this, We inquire Kato, Y. et al. about the utilization of wooden houses by Hazard Method ${ }^{5}$.

They are population statistics ${ }^{7}$ which are tempered by using reliability theory ${ }^{8)}$. Next sentences are

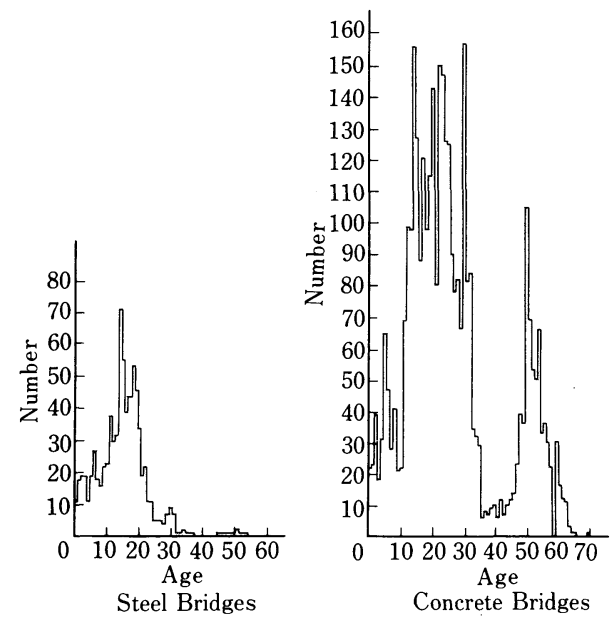

Fig. 1 Number and Age of Remaining Bridges.

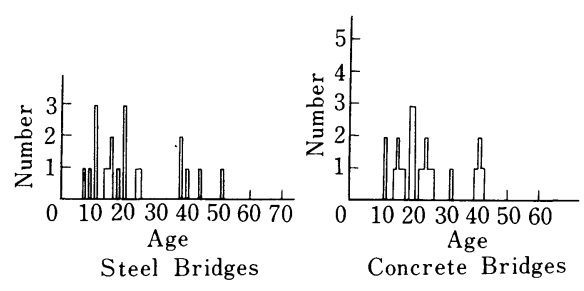

Fig. 2 Number and Age of Demolished Bridges. 
taken from references 5).

In reliability theory, reliability function can be notated as $R(t)$, and unreliability function as $F(t)=$ $1-R(t)$.

If $F(t)$ is differentiable then,

$f(t)=d F(t) / d t \quad$ probability density function of failure

$\lambda(t)=f(t) / R(t) \quad$ failure rate function

$\lambda(t)=(d F(t) / d t) / R(t)=(d(1-R(t) / d t) / R(t)=-(d R(t) / d t) / R(t)$

Integrate about $t$, from 0 to $t$, and regarding $R(0)=1$,

$$
R(t)=\exp \left(-\int_{0}^{t} \lambda(t) d t\right)
$$

$\int_{0}^{t} \lambda(t) d t$ is called Cumulated Hazard Function and notated as $H(t)$.

$\lambda(t)$ is the demolish ratio in place of breakdown ratio on bridge and is also a divisor of demolish number by remaining number in each age. Also, the number of reliability function represent the remaining rate.

In this study, the remaining ratio (reliability) function is estimated as demolish is equivalent to breakdown. For example, if demolish ratio of each age is $\lambda_{i}(i=0,100)$, the Sum of Hazard function $H(t)$ is nearly equal to $\sum_{0}^{t} \lambda_{i}$, owing to $(3)$,

$$
R(t)=\exp \left(-\sum_{0}^{t} \lambda_{i}\right)
$$

This is so called Cumulative Hazard Method and which are assumed to be non-parametric and is not affected by distribution shape of $R(t)$ and in this case is more reliable.

If some standard price is set against number of remaining ratio, average life time can be define. Usually, B 10 life (time of $10 \%$ demolished) or median (remaining ratio is less $50 \%$ ) is used.

2) Definition of average life expectancy, etc.

Accumulative Hazard Method is characteristic in presuming $R(t)$ curve, but since average life expectancy use the definition of population statistics ${ }^{9)}$, the relative terms can be written as follows.

(1) living rate $\quad p_{x}$

dying rate $\quad q_{x}$

(2) number of living $\quad l_{x}$

(3) number dying $\quad d_{x}$

(4) stationary population

If death and birth is stationary, population composition of age bracket converge on constant type. It can be called as stationary population and notated as ${ }_{n} L_{x}$ : more than $x$ age and less than $x+n$ age, notated as $T_{x}$ : more than $x$ age. That is,

$$
\begin{aligned}
& { }_{n} L_{x}=\int_{n}^{x+n} l_{x} d t \\
& T_{x}=\int_{x}^{\infty} l_{x} d t
\end{aligned}
$$

This is shown in Fig. 3. Area of $\mathrm{ABCD}$ is equivalent to ${ }_{n} L_{x}$ and area of $\mathrm{AB}$ further is $T_{x}$.

(5) Average life expectancy

Expected years which is the interval between $x$ age and the time of demolish is called average life expectancy of $x$ age and can be notated as $e_{x}^{0}$. Thus,

$$
e_{x}^{0}=T_{x} / l_{x}
$$

When $x=0$, it is the average life time.

In this paper, the oldest sample is 54 years for steel bridge and 70 years for concrete bridge where data are a few. By using the above methode, remaining ratio required is less than one per million, so the distribution shape of remaining ratio function should be estimated. 


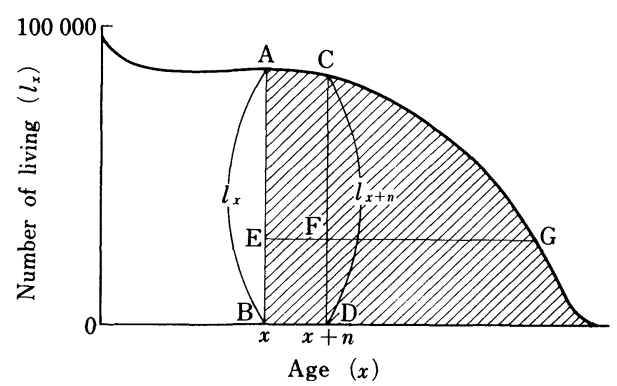

Fig. 3 Number of Living and Age.
Table 1 Grouping of Demolish Reason.

\begin{tabular}{c|l}
\hline \multicolumn{1}{c|}{ Old } & \multicolumn{1}{c}{ Old } \\
\hline & $\begin{array}{l}\text { Road improvement } \\
\text { River improvement } \\
\text { Special improvement } \\
\text { Administrative } \\
\text { scheme }\end{array}$ \\
& $\begin{array}{l}\text { Line improvement } \\
\text { Urban planning }\end{array}$ \\
\hline \multirow{2}{*}{ Social factor } & $\begin{array}{l}\text { Narrowness of width } \\
\text { Increase of traffic }\end{array}$ \\
\hline \multirow{2}{*}{ Natural factor } & $\begin{array}{l}\text { Under water } \\
\text { Ground settlement }\end{array}$ \\
\hline
\end{tabular}

3) Concrete analysing method

(1) It is supposed that life time test begin together as all bridge shift to one point in time.

(2) The remaining number, demolished number, ratio of demolish are arranged.

(3) The accumulated ratio of demolish, $R(t)$ and $F(t)$ are then calculated.

(4) In order to presume the distribution shape of $R(t)$, the relation between $t$ and $F(t)$ is plotted on Weibull's probability graph and logarithmic probability graph. As a result, $R(t)$ is supposed to follow Weibull's distribution.

(5) Weibull's parameter can be presumed from them and reliability analyse $\mathrm{e}^{10)}$ is done.

(6) From remaining ratio, average life time of each year is gained by population statics.

C) Analyse of demolish reason

1) Classification of demolish reason and treatment of data

There are many view of classification of demolish reason, here refering to the paper of Public Works Research Institute, Ministry of Construction, which are shown on Table 1. Then, characteristic factor diagram is drawn and combined with the pattern of demolish reason. It is common that more than two reason combine, and if $A$ and $B$ are both important, it will account $A=1$ and $B=1$.

2) The application of information theory

The contributed ratio of information is used. Each reason of demolish can be classified into $(A)$ happenable by years and $(B)$ happen without regard to years. The former has a contributed ratio of 1 and latter of 0 .

\section{THE RESULT OF THE ANALYSIS}

\section{(1) Life time}

a) Actual situation of remain and demolish of bridge devided annually

Reliability function $R(t)$ and unreliability function $F(t)$ are calculated from data of the remaining number, demolished number, demolish ratio for each years.

They are summed up into each category as steel and concrete bridge, where as for steel bridges is shown in Table 2. (below the samethings are being expressed.)

b) Estimating the distribution shape of $R(t)$

Trial adaptation of Weibull and logarithmic curve is shown Fig. 4. Since both is not so different, Weibull curve is chosen and each of its parameter are taken out.

(note: Weibull's function is suitable for the distribution of life time of manufactured goods and strength of material.)

c) The estimate of Weibull's parameter

Plotting in Weibull's paper, the parameter for steel bridge are, $m=2.1, t_{0}=8.2, \quad \gamma=0$ 
Table 2 Demolish Rate and Reliability Rate of Steel Bridges by Cumulated Hazard Methode.

\begin{tabular}{|c|c|c|c|c|c|c|}
\hline Age & $\begin{array}{l}\text { Remaining } \\
\text { Number }\end{array}$ & $\begin{array}{l}\text { Demolish } \\
\text { Number }\end{array}$ & $\begin{array}{l}\text { Demolish } \\
\text { Ratio } \lambda(\%)\end{array}$ & $\Sigma \lambda$ & $\begin{array}{l}R(t) \\
(\%)\end{array}$ & $\begin{array}{c}F(t) \\
(\%)\end{array}$ \\
\hline 0 & 11 & 0 & 0 & 0 & 100 & 0 \\
\hline 1 & 18 & 0 & 0 & 0 & 100 & 0 \\
\hline 2 & 19 & 0 & 0 & 0 & 100 & 0 \\
\hline 3 & 19 & 0 & 0 & 0 & 100 & 0 \\
\hline 4 & 11 & 0 & 0 & 0 & 100 & 0 \\
\hline 5 & 19 & 0 & 0 & 0 & 100 & 0 \\
\hline 6 & 27 & 0 & 0 & 0 & 100 & 0 \\
\hline 7 & 18 & 1 & 5.55 & 0.055 & 94.60 & 5.4 \\
\hline 8 & 16 & 0 & 0 & 0.055 & 94.60 & 5.4 \\
\hline 9 & 22 & 1 & 4.54 & 0.101 & 90.39 & 9.61 \\
\hline 10 & 23 & 0 & 0 & 0.101 & 90.39 & 9.61 \\
\hline 11 & 38 & 3 & 7.89 & 0.179 & 83.53 & 16.47 \\
\hline 12 & 30 & 0 & 0 & 0.179 & 83.53 & 16.47 \\
\hline 13 & 32 & 0 & 0 & 0.179 & 83.53 & 16.47 \\
\hline 14 & 72 & 1 & 1.38 & 0.193 & 82.38 & 17.62 \\
\hline 15 & 56 & $i$ & 1.78 & 0.211 & 80.92 & 19.08 \\
\hline 16 & 39 & 2 & 5.12 & 0.262 & 76.87 & 23.13 \\
\hline 17 & 44 & 0 & 0 & 0.262 & 76.87 & 23.13 \\
\hline 18 & 54 & 1 & 1.85 & 0.281 & 75.46 & 24.54 \\
\hline 19 & 46 & 0 & 0 & 0.281 & 75.46 & 24.54 \\
\hline 20 & 34 & 3 & 8.82 & 0.369 & 69.09 & 30.91 \\
\hline 21 & 19 & 0 & 0 & 0.369 & 69.09 & 30.91 \\
\hline 22 & 22 & 0 & 0 & 0.369 & 69.09 & 30.91 \\
\hline 23 & 10 & 0 & 0 & 0.369 & 69.09 & 30.91 \\
\hline 24 & 10 & 1 & 10.0 & 0.469 & 62.52 & 37.48 \\
\hline 25 & 5 & 1 & 20.0 & 0.669 & 51.18 & 48.82 \\
\hline 26 & 5 & 0 & 0 & 0.669 & 51.18 & 48.82 \\
\hline 27 & 5 & 0 & 0 & 0.669 & 51.18 & 48.82 \\
\hline 28 & 4 & 0 & 0 & 0.669 & 51.18 & 48.82 \\
\hline 29 & 7 & 0 & 0 & 0.669 & 51.18 & 48.82 \\
\hline 30 & 9 & 0 & 0 & 0.669 & 51.18 & 48.82 \\
\hline 31 & 7 & 0 & 0 & 0.669 & 51.18 & 48.82 \\
\hline 32 & 1 & 0 & 0 & 0.669 & 51.18 & 48.82 \\
\hline 33 & 1 & 0 & 0 & 0.669 & 51.18 & 48.82 \\
\hline 34 & 2 & 0 & 0 & 0.669 & 51.18 & 48.82 \\
\hline 35 & 0 & 0 & -- & & & \\
\hline 36 & 0 & 0 & -- & & & \\
\hline 37 & 1 & 0 & 0 & 0.669 & 51.18 & 48.82 \\
\hline 38 & 0 & 2 & -- & & & \\
\hline 39 & 0 & 0 & -- & & & \\
\hline 40 & 0 & 1 & -- & & & \\
\hline 41 & 0 & 0 & -- & & & \\
\hline 42 & 0 & 0 & -- & & & \\
\hline 43 & 0 & 0 & -- & & & \\
\hline 44 & 0 & 1 & -- & & & \\
\hline 45 & 0 & 0 & $\overline{0}$ & & & \\
\hline $\begin{array}{l}46 \\
47\end{array}$ & $\begin{array}{l}1 \\
0\end{array}$ & $\begin{array}{l}0 \\
0\end{array}$ & $\begin{array}{l}0 \\
--\end{array}$ & 0.669 & 51.18 & 48.82 \\
\hline 48 & 1 & 0 & 0 & 0.669 & 51.18 & 48.82 \\
\hline 49 & 0 & 0 & -- & & & \\
\hline 50 & 1 & 0 & 0 & 0.669 & 51.18 & 48.82 \\
\hline 51 & 2 & 1 & 50.0 & 1.169 & 31.04 & 68.96 \\
\hline 52 & 0 & 0 & -- & & & \\
\hline 53 & 1 & 0 & 0 & 1.169 & 31.04 & 68.96 \\
\hline 54 & 1 & 0 & 0 & 1.169 & 31.04 & 68.96 \\
\hline
\end{tabular}

d) The estimates of some scale of the distribution

The same as for steel bridge is (in year),

1) Particular life time $\eta=39.5$

2) Average life time $\mu=35.5$

3) Standard deviation $\sigma=22.9$

4) Median $\xi=31.0$

5) Mode $t_{m}=29.0$

e) Comparison of reliability rate and its sum 
Table 3 Comparison of Reliability Rate and Their Sum of Steel Bridges.

\begin{tabular}{|c|c|c|c|c|c|}
\hline Age & $\begin{array}{c}\mathrm{A} \\
R(t) \text { from Table } 2\end{array}$ & $\begin{array}{c}\text { B } \\
\text { Sum of } A\end{array}$ & $\begin{array}{c}\text { C } \\
R(t) \text { from }(4)\end{array}$ & $\begin{array}{c}\text { D } \\
\text { Sum of } C\end{array}$ & $\begin{array}{c}E \\
B-D\end{array}$ \\
\hline 0 & 1.0000 & 1.0000 & 1.0000 & 1.0000 & 0 \\
\hline 1 & 1.0000 & 2.0000 & 0.9996 & 1.9996 & 0.0004 \\
\hline 2 & 1.0000 & 3.0000 & 0.9981 & 2.9977 & 0.0023 \\
\hline 3 & 1.0000 & 4.0000 & 0.9956 & 3.9933 & 0.0067 \\
\hline 4 & 1.0000 & 5.0000 & 0.9919 & 4.9852 & 0.0148 \\
\hline 5 & 1.0000 & 6.0000 & 0.9871 & 5.9723 & 0.0277 \\
\hline 6 & 1.0000 & 7.0000 & 0.9811 & 6.9534 & 0.0466 \\
\hline 7 & 0.9429 & 7.9429 & 0.9739 & 7.9273 & 0.0156 \\
\hline 8 & 0.9429 & 8.8858 & 0.9695 & 8.8929 & -0.0071 \\
\hline 9 & 0.8990 & 9.7848 & 0.9562 & 9.8491 & -0.0643 \\
\hline 10 & 0.8990 & 10.6838 & 0.9457 & 10.7948 & -0.1110 \\
\hline 11 & 0.8252 & 11.5090 & 0.9340 & 11.7288 & -0.2198 \\
\hline 12 & 0.8252 & 12.3342 & 0.9213 & 12.6501 & -0.3159 \\
\hline 13 & 0.8252 & 13.1594 & 0.9076 & 13.5577 & -0.3983 \\
\hline 14 & 0.8136 & 13.9730 & 0.8929 & 14.4506 & -0.4776 \\
\hline 15 & 0.7992 & 14.7722 & 0.8773 & 15.3279 & -0.5557 \\
\hline 16 & 0.7572 & 15.5294 & 0.8608 & 16.1887 & -0.6593 \\
\hline 17 & 0.7572 & 16.2866 & 0.8435 & 17.0322 & -0.7456 \\
\hline 18 & 0.7430 & 17.0296 & 0.8253 & 17.8575 & -0.8279 \\
\hline 19 & 0.7430 & 17.7726 & 0.8085 & 18.6640 & -0.8914 \\
\hline 20 & 0.6745 & 18.4471 & 0.7870 & 19.4510 & -1.0039 \\
\hline 21 & 0.6745 & 19.1216 & 0.7669 & 20.2179 & -1.0963 \\
\hline 22 & 0.6745 & 19.7961 & 0.7463 & 20.9642 & -1.1681 \\
\hline 23 & 0.6745 & 20.4706 & 0.7253 & 21.6895 & -1.2189 \\
\hline 24 & 0.6036 & 21.0742 & 0.7038 & 22.3933 & -1.3191 \\
\hline 25 & 0.4701 & 21.5443 & 0.6820 & 23.0753 & -1.5310 \\
\hline 26 & 0.4701 & 22.0144 & 0.6600 & 23.7353 & -1.7209 \\
\hline 27 & 0.4701 & 22.4845 & 0.6378 & 24.3731 & -1.8886 \\
\hline 28 & 0.4701 & 22.9546 & 0.6154 & 24.9885 & -2.0309 \\
\hline 29 & 0.4701 & 23.4247 & 0.5930 & 25.5815 & -2.1568 \\
\hline 30 & 0.4701 & 23.8948 & 0.5705 & 26.1520 & -2.2572 \\
\hline 31 & 0.4701 & 24.3649 & 0.5482 & 26.7002 & -2.3353 \\
\hline 32 & 0.4701 & 24.8350 & 0.5259 & 27.2261 & -2.3911 \\
\hline 33 & 0.4701 & 25.3051 & 0.5038 & 27.7299 & -2.4248 \\
\hline 34 & 0.4701 & 25.7752 & 0.4820 & 28.2119 & -2.4367 \\
\hline 35 & -- & & 0.4604 & & \\
\hline 36 & -- & & 0.4391 & & \\
\hline 37 & 0.4701 & 26.2453 & 0.4182 & 28.6301 & -2.3848 \\
\hline 38 & -- & & 0.3978 & & \\
\hline 39 & -- & & 0.3777 & & \\
\hline 40 & -- & & 0.3582 & & \\
\hline 41 & -- & & 0.3391 & & \\
\hline 42 & -- & & 0.3206 & & \\
\hline 43 & -- & & 0.3027 & & \\
\hline 44 & -- & & 0.2853 & & \\
\hline 45 & -- & & 0.2685 & & \\
\hline 46 & 0.4701 & 26.7154 & 0.2523 & 28.8824 & -2.1670 \\
\hline 47 & -- & & 0.2368 & & \\
\hline 48 & 0.4701 & 27.1855 & 0.2219 & 29.1043 & -1.9188 \\
\hline 49 & -- & & 0.2076 & & \\
\hline 50 & 0.4701 & 27.6556 & 0.1939 & 29.2982 & -1.6426 \\
\hline 51 & 0.1729 & 27.8285 & 0.1808 & 29.4790 & -1.6505 \\
\hline 52 & -- & & 0.1684 & & \\
\hline 53 & 0.1729 & 28.0014 & 0.1566 & 29.6356 & -1.6342 \\
\hline 54 & 0.1729 & 28.1743 & 0.1454 & 29.7810 & -1.6067 \\
\hline
\end{tabular}

Weibull's distribution is usually written as,

$R(t)=\exp \left(-\left(\frac{t}{\eta}\right)^{m}\right)$

The value of $C$ and its sum $D$, the value of $R(t)$ which has been estimated from a) and its sum $B$ are shown is Table 3.

f) Calculating the life expectancy

Average life expectancy can be calculated by using the remaining rate in term of population statistics. The result is shown in the Form of Life Table in Table 4. The relation of remaining ratio and average life 


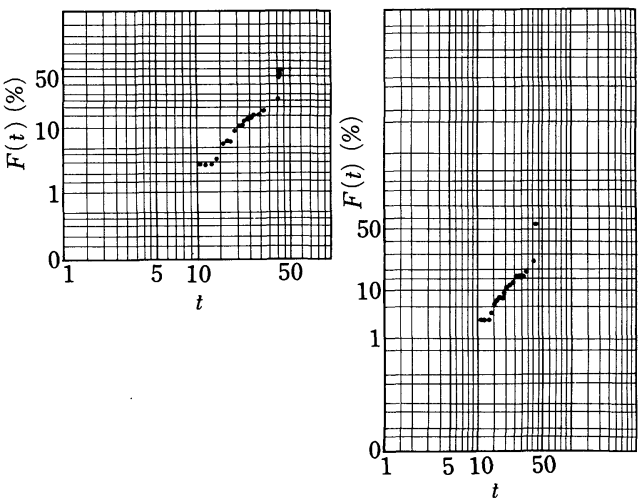

Fig. 4 Weibull's Probability Graph and Logarithmic Probability Graph of Steel Bridges.

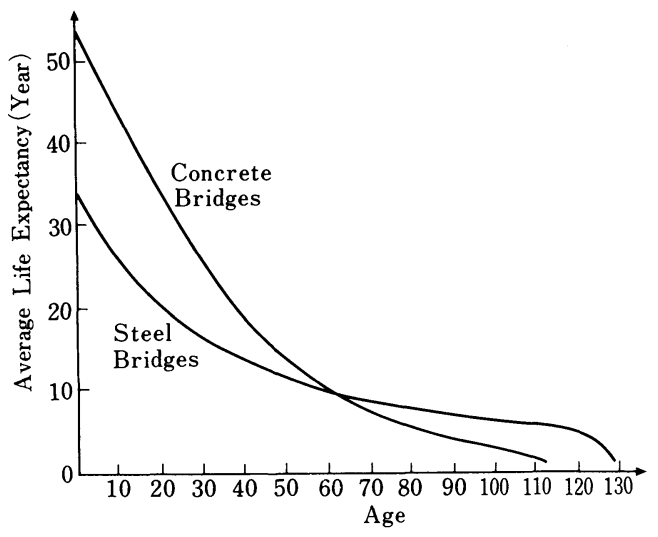

Fig. 6 Average Life Expectancy and Age.

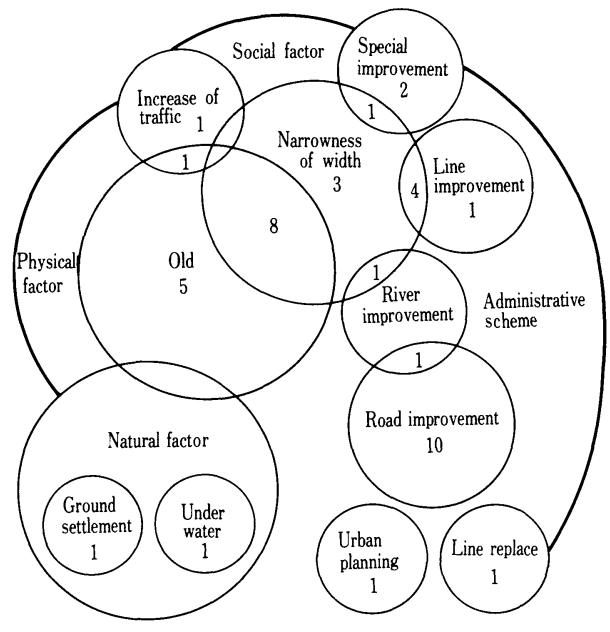

Fig. 8 Overlapping Pattern of Demolish Reason.

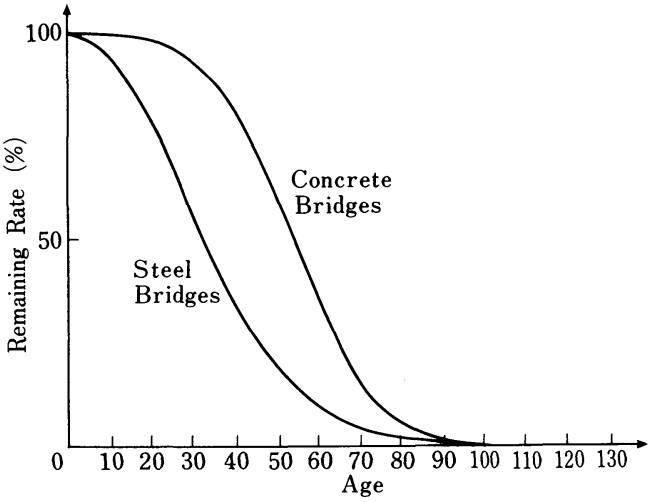

Fig. 5 Remaining Rate and Age.

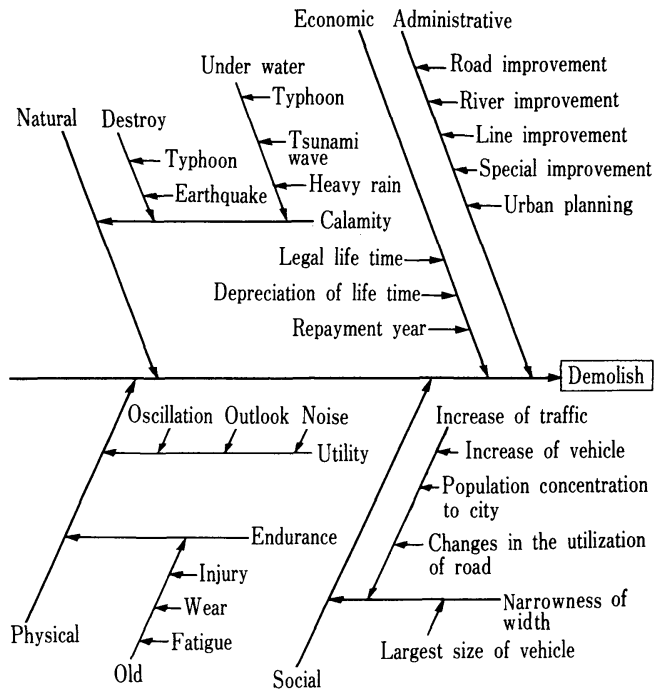

Fig. 7 Particular Factor Diagram of Demolish.

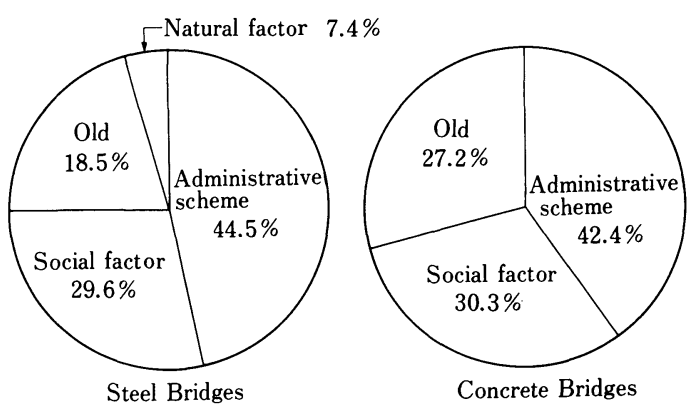

Fig. 9 Ratio of Demolish Reason. 
Table 4 Remaining Rate and Average Life Expectancy of Steel Bridges.

\begin{tabular}{|c|c|c|c|c|c|c|c|c|}
\hline Age & $\begin{array}{l}\text { Remaining } \\
\text { Rate }\end{array}$ & $\begin{array}{l}\text { Average } \\
\text { Life } \\
\text { Expectancy }\end{array}$ & Age & $\begin{array}{l}\text { Remaining } \\
\text { Rate }\end{array}$ & $\begin{array}{l}\text { Average } \\
\text { Life } \\
\text { Expectancy }\end{array}$ & Age & $\begin{array}{l}\text { Remaining } \\
\text { Rate }\end{array}$ & $\begin{array}{l}\text { Average } \\
\text { Life } \\
\text { Expectancy }\end{array}$ \\
\hline 0 & 1.00000 & 34.98 & 45 & 0.26850 & 12.80 & 90 & 0.00356 & 7.02 \\
\hline 1 & 0.99956 & 34.00 & 46 & 0.25233 & 12.60 & 91 & 0.00312 & 6.94 \\
\hline 2 & 0.99810 & 33.05 & 47 & 0.23678 & 12.39 & 92 & 0.00273 & 6.86 \\
\hline 3 & 0.99556 & 32.13 & 48 & 0.22185 & 12.19 & 93 & 0.00238 & 6.80 \\
\hline 4 & 0.99188 & 31.25 & 49 & 0.20755 & 11.99 & 94 & 0.00208 & 6.67 \\
\hline 5 & 0.98705 & 30.40 & 50 & 0.19388 & 11.80 & 95 & 0.00181 & 6.64 \\
\hline 6 & 0.98107 & 29.58 & 51 & 0.18083 & 11.62 & 96 & 0.00157 & 6.58 \\
\hline 7 & 0.97393 & 28.80 & 52 & 0.16841 & 11.44 & 97 & 0.00136 & 6.52 \\
\hline 8 & 0.96564 & 28.04 & 53 & 0.15660 & 11.27 & 98 & 0.00118 & 6.44 \\
\hline 9 & 0.96621 & 27.31 & 54 & 0.14540 & 11.10 & 99 & 0.00102 & 6.37 \\
\hline 10 & 0.94567 & 26.61 & 55 & 0.13479 & 10.93 & 100 & 0.00088 & 6.31 \\
\hline 11 & 0.93403 & 25.93 & 56 & 0.12476 & 10.77 & 101 & 0.00076 & 6.22 \\
\hline 12 & 0.92134 & 25.28 & 57 & 0.11531 & 10.61 & 102 & 0.00065 & 6.20 \\
\hline 13 & 0.90763 & 24.66 & 58 & 0.10641 & 10.46 & 103 & 0.00056 & 6.13 \\
\hline 14 & 0.89293 & 24.06 & 59 & 0.09804 & 10.31 & 104 & 0.00048 & 6.06 \\
\hline 15 & 0.87731 & 23.47 & 60 & 0.09019 & 10.16 & 105 & 0.00041 & 6.02 \\
\hline 16 & 0.86080 & 22.92 & 61 & 0.08284 & 10.02 & 106 & 0.00035 & 5.97 \\
\hline 17 & 0.84345 & 22.38 & 62 & 0.07598 & 9.88 & 107 & 0.00030 & 5.90 \\
\hline 18 & 0.82534 & 21.86 & 63 & 0.06957 & 9.74 & 108 & 0.00026 & 5.62 \\
\hline 19 & 0.80651 & 21.35 & 64 & 0.06361 & 9.61 & 109 & 0.00022 & 5.68 \\
\hline 20 & 0.78702 & 20.87 & 65 & 0.05807 & 9.48 & 110 & 0.00019 & 5.53 \\
\hline 21 & 0.76694 & 20.40 & 66 & 0.05292 & 9.36 & 111 & 0.00016 & 5.50 \\
\hline 22 & 0.74634 & 19.95 & 67 & 0.04816 & 9.23 & 112 & 0.00013 & 5.69 \\
\hline 23 & 0.72528 & 19.52 & 68 & 0.04375 & 9.11 & 113 & 0.00011 & 5.64 \\
\hline 24 & 0.70382 & 19.10 & 69 & 0.03970 & 8.99 & 114 & 0.00010 & 5.10 \\
\hline 25 & 0.68204 & 18.68 & 70 & 0.03596 & 8.88 & 115 & 0.00008 & 5.25 \\
\hline 26 & 0.65998 & 18.30 & 71 & 0.03252 & 8.76 & 116 & 0.00007 & 5.00 \\
\hline 27 & 0.63776 & 17.92 & 72 & 0.02936 & 8.65 & 117 & 0.00006 & 4.83 \\
\hline 28 & 0.61540 & 17.55 & 73 & 0.02647 & 8.54 & 118 & 0.00005 & 4.60 \\
\hline 29 & 0.59297 & 17.20 & 74 & 0.02382 & 8.44 & 119 & 0.00004 & 4.75 \\
\hline 30 & 0.57054 & 16.85 & 75 & 0.02141 & 8.33 & 120 & 0.00003 & 5.33 \\
\hline 31 & 0.54816 & 16.52 & 76 & 0.01921 & 8.23 & 121 & 0.00003 & 4.33 \\
\hline 32 & 0.52591 & 16.20 & 77 & 0.01721 & 8.13 & 122 & 0.00002 & 5.50 \\
\hline 33 & 0.50382 & 15.89 & 78 & 0.01539 & 8.04 & 123 & 0.00002 & 4.50 \\
\hline 34 & 0.48197 & 15.59 & 79 & 0.01374 & 7.95 & 124 & 0.00002 & 3.50 \\
\hline 35 & 0.46039 & 15.29 & 80 & 0.01225 & 7.86 & 125 & 0.00001 & 5.00 \\
\hline 36 & 0.43913 & 15.01 & 81 & 0.01091 & 7.76 & 126 & 0.00001 & 4.00 \\
\hline 37 & 0.41824 & 14.73 & 82 & 0.00970 & 7.67 & 127 & 0.00001 & 3.00 \\
\hline 38 & 0.39776 & 14.47 & 83 & 0.00860 & 7.59 & 128 & 0.00001 & 2.00 \\
\hline 39 & 0.37772 & 14.21 & 84 & 0.00762 & 7.50 & 129 & 0.00001 & 1.00 \\
\hline 40 & 0.35856 & 13.96 & 85 & 0.00674 & 7.42 & 130 & 0.00000 & 0.36 \\
\hline 41 & 0.33912 & 13.71 & 86 & 0.00595 & 7.34 & & & \\
\hline 42 & 0.32060 & 13.48 & 87 & 0.00525 & 7.22 & & & \\
\hline 43 & 0.30265 & 13.23 & 88 & 0.00462 & 7.17 & & & \\
\hline 44 & 0.28528 & 13.02 & 89 & 0.00406 & 7.10 & & & \\
\hline
\end{tabular}

expectancy in term of year are shown in Fig. 5 and Fig. 6.

\section{(2) Analysing of demolish reason}

a) Particular factor diagram and combination of demolish reason

In considering the demolish reason, particular factor diagram ${ }^{(6) .11)}$ is drawn and shown in Fig. 7. Almost all of the demolish reason are overlapped to each other, thus the overlapping pattern are analysed as shown in Fig. 8.

b) Demolish reason and using year

Demolish reason are devided roughly into 4 groups as it is shown 2.(2) c) and each gains its utilization time. For example, on steel bridge,

$\begin{array}{lrl}\text { old } & 5 \text { case } & 34.6 \text { year } \\ \text { administrative scheme } & 12 & 15.5 \\ \text { social factor } & 8 & 24.3 \\ \text { natural factor } & 2 & 22.5 \\ \text { total } & 27 & 22.2\end{array}$




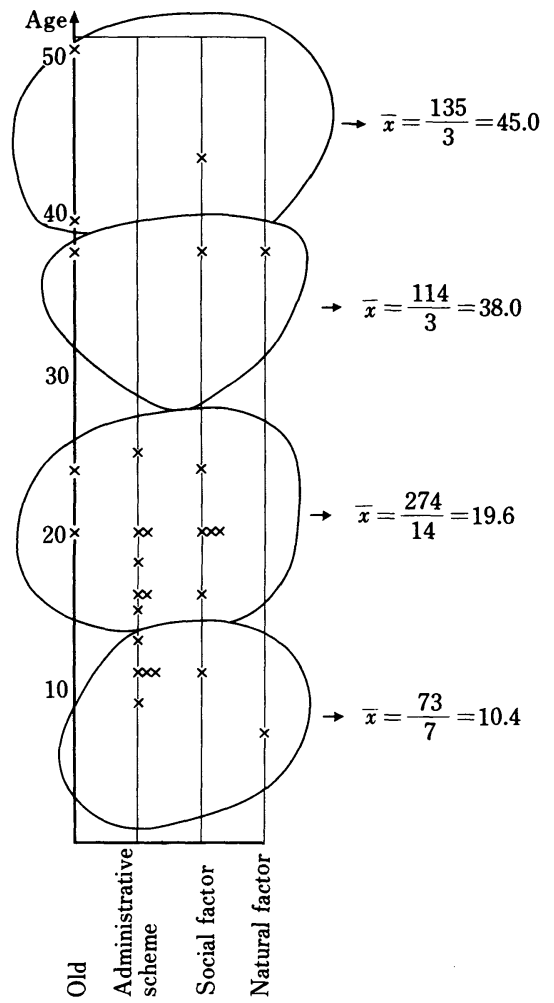

Table 5 Information Matrix (Steel Bridges).

\begin{tabular}{l|l|c|c|c|c}
\hline \multirow{2}{*}{$\begin{array}{c}\text { Using year }(x) \\
\text { Demolish reason }(y)\end{array}$} & \multicolumn{4}{|c}{ Information source } \\
\cline { 3 - 6 } & 10.4 & 19.6 & 38.0 & 45.0 \\
\hline \multirow{4}{*}{$\begin{array}{l}\text { Infor- } \\
\text { mation } \\
\text { path }\end{array}$} & \begin{tabular}{l} 
Old \\
\cline { 2 - 6 } \\
scheme
\end{tabular} & & 2 & 1 & 2 \\
\cline { 2 - 6 } & Social factor & 1 & 5 & 1 & 1 \\
\cline { 2 - 6 } & Natural factor & 1 & & 1 & \\
\hline
\end{tabular}

Table 6 Demolish Reason and its Contributed Rate of Information (Steel Bridges).

\begin{tabular}{l|c}
\hline \multicolumn{1}{c|}{ Demolish reason } & $\begin{array}{c}\text { Contributed rate } \\
\text { of information }\end{array}$ \\
\hline Natural factor & 0.514 \\
Old & 0.259 \\
Administrative scheme & 0.227 \\
Social factor & 0.000 \\
\hline \multicolumn{1}{c}{ Sum } & 1.000 \\
\hline
\end{tabular}

Fig. 10 Relation of Demolish Reason and Life Time (Steel Bridges).

c) ratio of demolish reasons

Ratio of each 4 reasons against all are shown in Fig. 9.

d) calculation result of the contributed rate of information

From the data of demolished bridge (steel 20, concrete 24, total 44), the information matrix of the demolish reason and utilization year are solved.

In case of steel bridge, the relation of demolish reason and life time are shown in Fig. 10, and the information matrix as Table 5 and contributed rate of information as Table 6.

It may be supposed from this results that the life time of bridge are often determined by other fact before physical life time is reached and from view of information theory they are considered as unexpectable. So, it is necessary to view it from social change, administrative, economic circumstances.

\section{CONCLUDING REMARKS}

In this study, it is supposed that the average life expectancy for steel bridges is about 35 years and for concrete bridges is about 54 years. For steel bridges, it seemed to be too short because of the insufficiency of sample, but it can be supposed more durable than concrete bridges since the rate of curve is small.

It would be noticed that this is a calculated value by theoretical reasoning not for bridges which are constructed nowadays in the same way as that average of real life time of newborn baby in some year is not accord with expectancy of 0 year in demography.

Anyway, this value will be useful as a standard when planning and management are schemed. It is a matter of thing for maintenance to know the expectancy of existing bridge for every year class, rather than new constructed bridge. 
Concerning the analysis of demolish reason, this study is started from various life time reason, so it is important to be more thoroughly researched. Grouping is shown as one possible way, but many opinion would be expected.

Using a classification made by the Ministry of Construction concerning administrative scheme it gets more than half and by adding social factor it reachs $3 / 4$. As for year of utilization, old is the longest. This shows that the life time of bridge are reached by another external reason rather than only physical reason.

And from the view of contributed rate of information, they are considered as unexpectable factor, so very difficult problems appear in maintenance matter. So, in order to maintain bridges, usually the tendency of social, economic, politic change that influence its life time should be recognized.

To exercise more reliably, this study should be expanded to national scale and increased many bridges. And the difference of many factors of region, climate, etc. should be included.

\section{ACKNOWLEDGEMENT}

Sincery gratitude is expressed to Mr. Ayato MATSUGO, Takeshi KAMINISHI and other staff members of Civil Engineering Department of Niigata prefecture who supply the data and give advice; to Mr. Shinobu OYANAGI who help this work as graduation diploma.

\section{REFERENCES}

1) J. S. C.E. Kansai Branch: Endurable performance and of existing bridges, text of lecture class, 1985.7.

2) Kunihiro, T. : Bearing force judgement of road bridges, Bridge and Foundation, 1984.10.

3) Kobori, T. et al. : A Special Number on Life Time and Maintenance of Civil Engineering Structures, Proceedings of Japan Society of Civil Engineering, 1979.3.

4) Watanabe, N. : On Life Time of Bridges, Bridges and Foundations, 1979. 3.

5) Kato, Y. and Komatsu, Y. : A Statistical Study of Life Time of Japanese Wooden Houses, Journal of Japan Architectural Institute, Plan and Environment Engineering. Vol. 363, 1986.5.

6) Iizuka, H. and Yamaguchi, K. : Optimum Building Maintenance Regarding Usuable Years, Journal of Japan Architectural Institute, No. 171, 1970.5.

7) Tachi, M. : Introduction to Formal Demography, Kokon Bookshop, 1963.

8) Shiomi, H. : Introduction to Reliability Engineering, Maruzen Co., 1982.

9) Editing of Ministery of Health and Welfare, The 15-th Life Tables, Statistics and Information Department Minister's Secretariat, 1986.

10) J. U. S. E. : Analysis of reliability data, using way of Weibull probability paper, 1967.

11) Operations Research Committee of N. T. T. ; Report on Optimize of Maintenance Cost of telephon and telegraph building, 1968. 7 .

(Received March 26 1987) 